\title{
Multi Objective Generation Dispatch of a Hybrid System with Fuzzy based Space Search Algorithm
}

\author{
Prakash Kumar $\operatorname{Hota}^{1}$, Nakul Charan Sahu ${ }^{2}$ and Ajit Kumar Barisal ${ }^{1}$ \\ ${ }^{1}$ Department of Electrical Engineering, V.S.S.U.T, Burla, Odisha, India \\ ${ }^{2}$ Department of Electrical Engineering, I.T.E.R, Bhubaneswar, Odisha, India \\ p_hota@rediffmail.com
}

\begin{abstract}
This paper presents a new approach to the solution of optimal power generation for economic emission load dispatch (EELD) using space search algorithm to a hybrid power system. The proposed space search algorithm (SSA) has been applied on 23 benchmark test functions and the results were compared with Gravitational search algorithm (GSA), Particle swarm optimization (PSO), Differential evolution (DE) and Grey wolf optimizer (GWO). The results show that SSA method is able to provide very competitive results compared to other established meta-heuristics. After that, the economy objective function is minimized, followed by minimization of emission level objective function. Then, both the objectives are combined through a fuzzy coordination method to form a fuzzy decision making (FDM) function. Maximizing the FDM function then solves the original two-objective problem. The minimization and maximization tasks of this optimization problem are solved by the space search algorithm. The optimisation technique was applied to the hybrid system and a conventional power system with only three conventional thermal generators. The results by hybrid system provide cheaper generation schedule in comparison to individual system of thermal generators.
\end{abstract}

Keywords: Economic Emission Load Dispatch; Space Search Algorithm; Fuzzy Decision Making; Two-Objective Problem; Hybrid System

\section{Introduction}

The economic emission load dispatch problem is a complex nonlinear constrained optimization problem, which is to allocate optimal amount of generated power for the fossil based generating units in the system by minimizing the fuel cost and emission level simultaneously, subject to system constraints. With growing demands, the production of more energy has led to larger scale of pollution. So, the prime objective in scheduling the thermal generators will be to reduce the fuel cost which results in profit and also saving the natural resources. Thermal energy, though an efficient and easily harnessed energy source, causes a wide spread pollution to natural resources like soil, air and water. An alternative to remove dependency on thermal power plant to meet the load demand will be helpful. Moreover, renewable energy sources cannot meet the load demand independently due to limitations in harnessing. A mix in generation by using hybrid systems, i.e. a mixture of renewable energy sources and conventional thermal power plants can solve both the problems.

The author John Hetzer et al. [1] has proposed to include the wind energy conversion system (WECS) generators in the economic dispatch problem. In this paper he has included the overestimation and underestimation penalty factors to the wind farms in the classic dispatch factors. Edgardo D. Castronuovo et al. [2] have proposed the utilization of water storage ability to improve wind park operational economic gains and to attenuate the active power output variations due to intermittence of the wind-energy resource. The stochastic characteristics of the wind power are exploited in the approach developed in order to obtain a recommended operational condition. J Garcia-Gonzalez et al. [3] have proposed the use of hydro-pumped storage units as a good complement to wind generation due to their ability to manage positive and negative energy imbalances over time. The problem is formulated by taking two random

Received: December $8^{\text {th }}, 2014$. Accepted: August $23^{\text {rd }}, 2016$ 
parameters: market price and wind generation. V.S. Pappala et al. [4] have addressed a multistage stochastic model for the optimal operation of wind farm, pumped storage and thermal power plants. In this paper the output of wind farm and the electrical demand are considered as two independent stochastic processes. Eleanor Denny et al. [5] have tried to reduce the emission levels by the use of wind energy. They have developed a despatch model to analyze the impact of wind generation on the operation of conventional plants and emission of $\mathrm{CO}_{2}, \mathrm{SO}_{2}$ and $\mathrm{NO}_{\mathrm{X}}$. A.T. Al-Awami et al. [6] have formulated a dispatch solution with wind and thermal units taking into account the stochastic nature of wind power output and the imbalances charges due to the mismatch between the actual and scheduled wind power outputs. They have proposed an enhanced multi-objective particle swarm optimization to search for the set of Pareto-optimal solutions that is the best compromising solution for least emission and best cost. This proposed technique has been helpful for the system operators to operate the grid with high penetration of wind power more efficiently while maintaining emissions within restricted limit. In another paper, V. Miranda et al. [7] have successfully developed an economic dispatch model with fuzzy wind constraints and attitudes of dispatchers. Tzyy_Chyang Lu et al. [8] have proposed an optimization method combined with Evolutionary space search algorithm (ESSA). The main aim of ESSA is to divide the feasible solution space into many subspaces and search for the solution by finding the optimal subspaces. These process increases the probability of selecting subspaces that generates better fitness. To find out the best subspace combination effectively and prevent premature convergence, an overlapping strategy is proposed to encode subspace. In concluding the paper ESSA searches the optimal solution by finding correct subspaces. W. Huang et al. [9] reported the potential of space search optimization with accelerated convergence strategies. S. Papaefthimiou et al. [10] have proposed the use of Pumped storage as the most suitable storage technology for achieving high wind penetration levels in multi-MW sized autonomous island grids, where the technical constraints introduced by the conventional generating units impose limitations on the output of wind farms. In this paper they have proposed an operating policy for hybrid wind-hydro power stations in island grids, in order to increase wind penetration. M. Tripathy et al. [11] have applied Bacteria foraging optimization to probabilistic wind model in economic load dispatch problem. Warsono et al. [12] have reported the genetic algorithm based approach to model the intermittent resources as negative load. To the best of the authors knowledge, this new space search algorithm is hardly applied to engineering problems. To validate the proposed method, it has been applied to 23 standard benchmark functions [13-22]. Then, the results obtained from Space search algorithm (SSA) method outperform when compared with Gravitational search algorithm (GSA) and Grey wolf optimizer (GWO) in almost all cases. The current research is focused at usage of renewable energy in existing power grids and optimizing grid objectives such as cost, reliability, environmental impact, customer preferences, etc. Here a hybrid model has been formulated for economic emission dispatch of the system with a wind farm, a pumped storage unit and three conventional thermal power plants by using the proposed space search algorithm.

\section{The Hybrid System}

The hybrid system comprises of three conventional thermal generators, a wind generator and also a pumped storage plant. In the proposed hybrid system, three prime objectives are met which follows as minimization of cost, minimization of emission and best compromised solution of cost and emission.

\section{A. Wind power units}

The wind power penetration to a system is modelled in two ways. The first one is the probabilistic wind turbine cost model and another is the negative load model. A probabilistic model for the wind turbine output based on the Weibull probability density function accounts for both overestimation and underestimation of available wind power [11]. In the negative load 
model all the forecasted wind power will be used to calculate the new load by subtracting the wind power from the total load [12].

Wind power is clean source and after initial fixed cost it has practically less operating cost. The wind power being dependent on speed and direction of wind, so is the power contributed to the hybrid system. Here, the Wind Energy Conversion System (WECS) output is used to transform wind speed to the power output considering the wind farm as a single unit. The wind power output is obtained from the predicted wind speed as follows.

$$
\begin{aligned}
& P w(t)=0 \text { for } V(t) \geq V_{c o} \text { or } V(t)<V_{c i} \\
& P w(t)=P_{r} * \frac{\left[V(t)-V_{c i}\right]}{\left[V_{r}-V_{c i}\right]} \text { for } V_{c i} \leq V(t)<V_{r} \\
& P w(t)=P_{r} \text { for } V_{r} \leq V(t)<V_{c o}
\end{aligned}
$$

Thus, it is seen that power is generated only within cut in and cut out speed.

Due to the stochastic nature of wind, wind farms are imposed with overestimation and underestimation penalty factors. If a certain amount of wind power is assumed and that power is not available at the assumed time, power must be purchased from an alternate source or loads must be shed. So, a penalty called as overestimation penalty has to be imposed on the farm. If the available wind power is actually more than what was assumed, then dummy load resistor need to be connected to waste the surplus power resulting in underestimation penalty.

For simplicity, the negative load model is used in the present study for solving the economic emission dispatch problem. The coordinated operation of Pumped storage plant and daily wind power availability provides significant generation during scheduled period and ensuring positive generation (generator) or negative generation (motoring). To meet the load demand, the remaining power is produced by thermal plants in a hybrid system

\section{B. Pumped storage unit}

It is a hydro plant with a head and tail reservoir. During peak hour the turbine drives the generator and the plant generates electrical energy while during off peak hours the generator operates as a motor and drives the turbine which now works as a pump raising the water from the tail water reservoir to the head water reservoir, thereby reducing the capital cost of the plant and improving the operating efficiency.

The daily operation of pumped storage is modeled as follows:-

Generating mode

$$
P L_{t+1}=P L_{t}-M * P G_{t} / \eta_{g}
$$

Pumping mode

$$
\begin{aligned}
& P L_{t+1}=P L_{t}+M * P P_{t} * \eta_{p} \\
& P G_{\text {Min }, t} \leq P G_{t} \leq \operatorname{Min}\left(P D_{\text {Max }, t}, \eta_{g} * P L_{t} / M\right) \\
& P P_{\text {Min }, t} \leq P P_{t} \leq P P_{\max , t} \\
& P L_{\text {Min }, t} \leq P L_{t} \leq P L_{\text {max }, t}
\end{aligned}
$$

Pumped storage hydro has provided significant benefits to our energy supply system including storage, load balancing, frequency control, resource generation. 
The advantages of pumped storage plant in hybrid system are given below.

- Rapid response to offset wind generator variability.

- Store wind energy during off-peak periods of load demand.

- Prevent wind curtailment and avoid new transmission on investments.

- "Shape" prices by optimizing schedules of wind generator output and storage.

- Allows for better integration of renewable energy into the power grid.

The disadvantages of pumped storage plant in hybrid system are given below.

- Capital and operating costs of the combined wind and pumped storage is complex.

- Energy losses (about 25\%) related to pumped storage.

\section{Combined operation of wind farm and pumped storage unit}

During high wind power generation, the pumped storage unit works as motor and lifts the water to the upper reservoir and use it when the demand on system increases or when the wind power generation is lower than the predicted value. The combination has certain advantages like the combination produces a constant output irrespective of wind speed, removing the problems of overestimation or underestimation penalty factors on wind farms and ensuring a higher minimum power delivery to the grid. As the power output of wind power plant depends upon the velocity and direction of wind hence, it becomes stochastic in nature. The output of wind plant in this case varies from $10 \mathrm{MW}$ to $45 \mathrm{MW}$. In this hybrid system a base power of 30 MW is selected from wind plant to meet the load demand. When wind generation exceeds the base power of $30 \mathrm{MW}$, it is assumed as over generation and we go for energy storage as in pumped storage power plant, i.e., the water is pumped from lower reservoir to upper reservoir by the motoring mode. Whenever, wind power is less than $30 \mathrm{MW}$ and then the pumped storage plant generates power in generating mode. In this way both the plants are operated in a coordinated way to level the load balance of the hybrid system and enhancing the efficiency of system by saving energy.

\section{Thermal units}

In thermal power plant the steam produced by boilers utilizing heat from combustion of fossil fuels is used to drive the Turbo-generator set to produce electrical power. The fuel cost function of each unit considering the valve-point effects is expressed as the sum of a quadratic and a sinusoidal function. The total fuel cost in terms of real power output can be expressed as:

$$
O C\left(P_{i}\right)=a_{i}+b_{i} * P_{i}+c_{i} * P_{i}^{2}+a b s\left[d_{i} *\left\{\sin \left(e_{i} *\left(P G_{M i n, i}-P_{i}\right)\right)\right\}\right]
$$

Where $a_{i}, b_{i}, c_{i}, d_{i}$ and $e_{i}$ are the cost coefficients of the $i^{\text {th }}$ thermal unit.

Mainly, three polluting gases are released from the thermal power plants viz. $\mathrm{CO}_{2}, \mathrm{SO}_{2}$ $\mathrm{SO}_{2}$ and $N O_{X}$. Considering the thermal plants the major source of emission is $N O_{X}$ and accordingly this study is focused on the emission of $N O_{X}$. The total emission in the system is expressed as:

$$
\operatorname{Emc}\left(P_{i}\right)=\gamma_{i}+\beta_{i} * P_{i}+\alpha_{i} * P_{i}^{2}+\eta_{i} *\left\{\exp \left(k_{i} * P_{i}\right)\right\}
$$

Where, $\gamma_{i}, \beta_{i}, \alpha_{i}, \eta_{i}$ and $k_{i}$ are the emission coefficients of the $i^{\text {th }}$ thermal unit.

\section{Problem Formulation}

In the problem formulation of economic emission generation dispatch, three prime objectives are met which follows as: (a) Economic dispatch, (b) Least emission dispatch and (c) Economic and least emission dispatch. 


\section{A. Economic dispatch}

Economic dispatch deals with the minimization of cost of power production is primarily targeting to find the optimal allocation of the electrical power output from various available generators with given constraints. These constraints typically take the form of minimum and maximum generator outputs. Here, the objective function is the minimization of the cost.

$$
J_{1}=\operatorname{Min} \sum_{i=1}^{n} O C\left(P_{i}\right)
$$

\section{B. Least emission dispatch}

The total amount emission level from all the units in the system can be expressed as:

$$
J_{2}=\operatorname{Min} \sum_{i=1}^{n} \operatorname{Emc}\left(P_{i}\right)
$$

\section{Economic and least emission dispatch}

Since, $J_{1}$ and $J_{2}$ are dependent on one another it is better to minimize them independently to get the trade off curve. Both the objectives $J_{1}$ (cost) and $J_{2}$ (Emission) are conflicting in nature. Fuzzy logic is considered to be very suitable to address the combined objectives $J_{3}$ satisfactorily. The approach in this case is to find the best compromised solution from the possible set of solutions, considering the two objectives simultaneously with the help of fuzzy logic coordination method.

$$
J_{3}=\operatorname{Min} \sum_{i=1}^{n}\left\{O C\left(P_{i}\right)+C F * \operatorname{Emc}\left(P_{i}\right)\right\}
$$

\section{Space Search Algorithm}

The algorithm is used to find the most optimal allocation of the generation schedule for all the three objective functions by search space algorithm. In this algorithm, the whole search space is divided into many subspaces and search for the solution by finding the optimal space. According to fitness value in each generation the subspaces areas are selected. This process increases the probability of selecting subspaces that generates better fitness and enables the algorithm to exploit good subspaces. The probability of getting trapped by local optima is less as the reduction of search space from generation to generation. The algorithm randomly searches in each search space (local search) and then the other search spaces to find the optimal search space. The complementary search space of each search space (global search space) is calculated [9]. The position of maximum and minimum objective function value decides the boundary of next search space (reduced). The point of solution becomes closer and closer to global optimum as the search space is gradually reduced in successive generations.

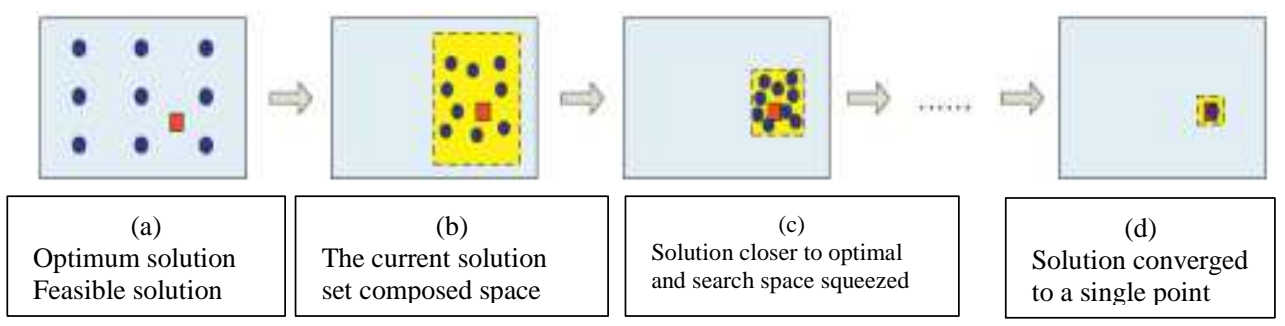

Figure 1. A concept of reduced search space developed in successive generations 
This figure 1 indicates a process of traversing the search space of the proposed algorithm in successive iterations. The current solution is constantly updated by new solutions (generation of new offspring). During generations of new solutions, the search space based on current solutions becomes smaller and smaller. The refinement solution takes place till the last generation. Then the current solutions are converged to same global optimum and corresponding search space squeezes to a single point. So, all the solutions in the current population have the same fitness. The method terminates after a predefined maximum number of generations is reached.

The flow chart of the proposed algorithm is shown in figure. 2. This algorithm is given below in details by the following steps.

\section{A. Algorithm Procedure}

Sample solutions are randomly generated with uniform distribution over the whole space. No of samples are predefined.

Step 1. After initialization, the value of the objective function is determined for each sample solutions.

Step 2. Position of the maximum and minimum values of the objective function is noted. This position becomes the boundary of the next search space (local search).

Step 3. The next search space is reduced as the boundary restricts the value in it. Now again sample solutions are randomly generated with uniform distribution in the complementary reduced space (global search space).

Step 4. To rule out the possibly of the local optimum point, position of the maximum and minimum values of the objective function is noted again in the complementary space (global search space).

Step 5. The position of maxima and minima that we get in step 3) and in step 5) is compared. Whichever is the true minima and maxima, that space is chosen as next reduced sample space.

Step 6. Steps from 2) to 6) are repeated till finally getting the maximum and minimum values as same. The sample space then reduces to a point. The details about the algorithm are given in reference [8], [9].

The mathematical details, procedure of local search and global search and pseudo code of space search algorithm are clearly described in reference [9].

\section{B. Best compromise solution}

The fuzzy set theory has been implemented to derive efficiently a solution from the set of non-dominated solutions. The fuzzy decision making function is represented by the membership function to replace each variable as a precise value. Figure. 3 depicts the membership function $\mu_{c}$ for the fuzzy variable signifying total fuel cost $f_{i}\left(P G_{i}\right)$. The decision maker is fully satisfied with the cost if, $\mu_{c}=1$, and not satisfied at all if $\mu_{c}=0$. Therefore, the value of membership function indicates the adaptability of the economy index. Due to the imprecise nature of decision maker's judgment, the $i^{\text {th }}$ objective function of a solution in the non-dominated set $f_{i}\left(P G_{i}\right)$ is represented by a membership function $\mu_{i}\left(P G_{i}\right)$ defined as: 


$$
\mu_{i}\left(P G_{i}\right)=\frac{\left\{f_{i}^{\max }-f_{i}\left(P G_{i}\right)\right\}}{\left\{f_{i}^{\max }-f_{i}^{\min }\right\}}
$$

Where, $f_{i}^{\max }$ and $f_{i}^{\min }$ are the maximum and minimum values of $i^{\text {th }}$ objective, respectively.

Then the fuzzy decision making function (FDM) is described as:

$$
F D M_{i}\left(P G_{i}\right)=\left\{\begin{array}{ccc}
0 & \text { for } & \mu_{i}\left(P G_{i}\right) \leq 0 \\
\mu_{i}\left(P G_{i}\right) & \text { for } & 0<\mu_{i}\left(P G_{i}\right)<1 \\
1 & \text { for } & \mu_{i}\left(P G_{i}\right) \geq 1
\end{array}\right.
$$

For each non-dominated solution $\mathrm{k}$, the normalized membership function is known as fuzzy decision making function ( $F D M^{k}$ ) which is given below.

$$
F D M^{k}=\frac{\sum_{i=1}^{2} F D M_{i}^{k}\left(P G_{i}\right)}{\sum_{j=1}^{M} \sum_{i=1}^{2} F D M_{i}^{j}}
$$

The best compromising solution of EELD problem is the one having the maximum value of $F D M^{k}$ as fuzzy decision making function. Where, $M$ is the total number of non-dominated solutions. Then all the solutions are arranged in descending order according to their membership function values which will guide the decision makers with a priority list of nondominated solutions in view of the current operating conditions.

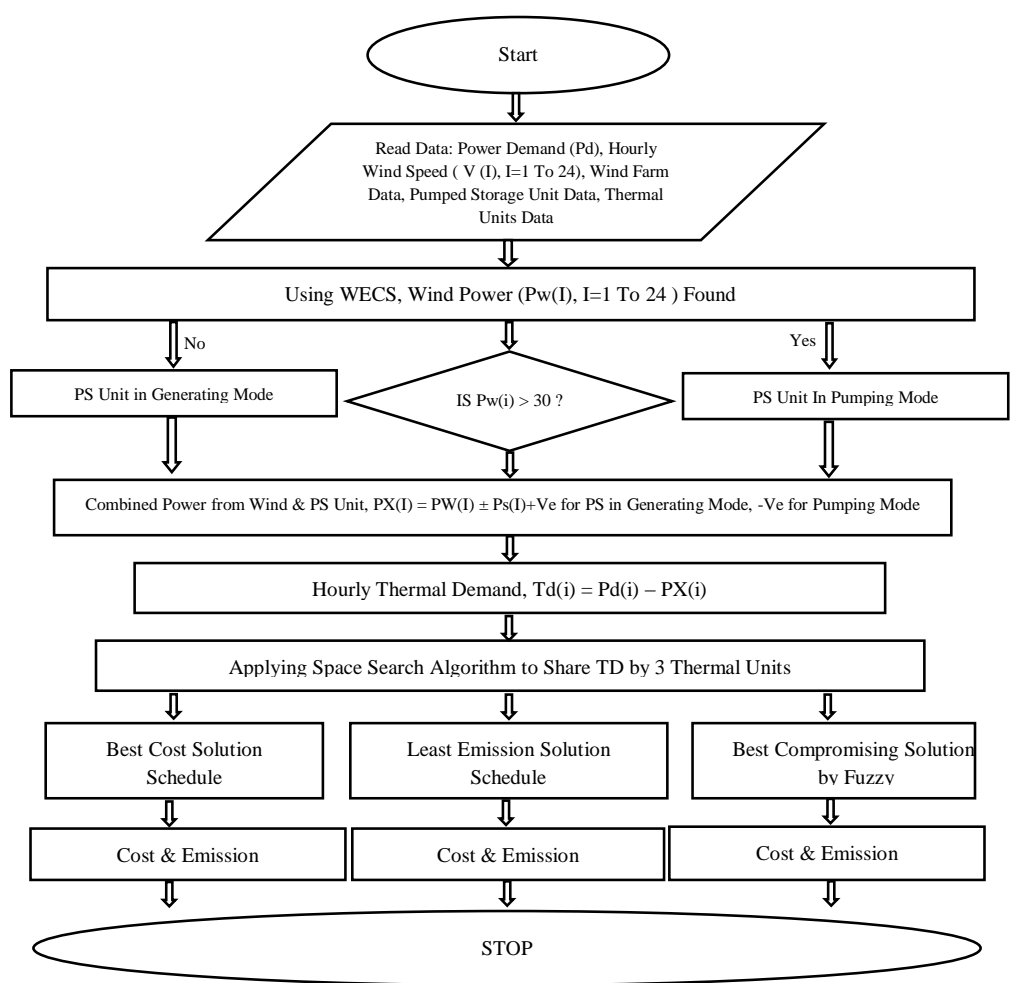

Figure 2. Flow chart of the proposed space search algorithm 


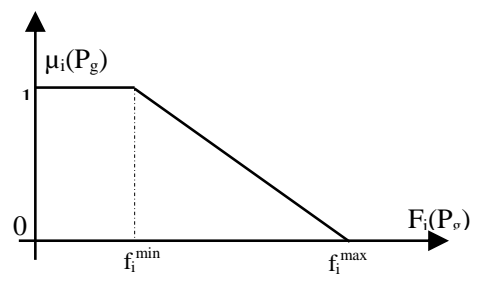

Figure 3. Membership function of fuzzy fuel cost

\section{Application of space search algorithm}

The results are provided in next section when space search algorithm is applied for scheduling three conventional thermal generators. In each of iteration, the maximum limit is reduced and minimum limit is raised so that the space to be searched for the scheduling is reduced. This process continues till we arrive at a point where the maximum and minimum limit is the same. So, we find that with each of iteration the net space to be searched is being reduced. When the maximum limit and minimum limit nearly coincide we find that the space to be searched has been reduced to a point and that position is the optimized solution schedule.

\section{Results and Discussion}

\section{A. Benchmark functions}

The proposed space search algorithm (SSA) as well as gravitational search algorithm (GSA), PSO, DE and grey wolf optimization (GWO) have been applied to 23 standard benchmark functions to evaluate their performances. Three types of functions are experimented in this study and are reported in Tables 1-3. Table 1 represents the unimodal benchmark functions with functions $F_{1}$ to $F_{7}$, the multimodal benchmark functions $F_{8}$ to $F_{13}$ are provided in Table 2 and the fixed dimension multimodal functions $F_{14}$ to $F_{23}$ are also provided in Table 3. The above mentioned three heuristic methods have been applied to these minimization test functions and their results are compared. In all these cases, the population size is set to 50, dimension is 30 and maximum number of iterations is 500 for functions of Tables 1,2 and 3 . The result obtained by SSA method is averaged over 30 runs and the average value and the standard deviation of unimodal functions F1 to F7 are compared with DE, PSO, GSA and GWO [22] methods and reported in Table 4.

Similarly, the average value and standard deviation of multimodal test functions $F_{8}$ to $F_{13}$ and fixed dimension multimodal functions $F_{14}$ to $F_{23}$ by SSA method are reported in Tables 5 and 6 , respectively. The results of SSA method have been compared with PSO, DE, GSA and GWO [22] methods and reported in Tables 5 and 6. Considering the results obtained for three types of test functions from $F_{1}$ to $F_{23}$, it is observed that all three heuristic methods have been able to find the global minimum with varying execution time. The interesting point of SSA might be its faster convergence except $F_{6}, F_{13}$ and $F_{23}$ test functions. The minimum function value is found by SSA in almost all cases except $F_{6}, F_{13}$ and $F_{21}$ functions. So, SSA is considered as a competitive new algorithm like GWO.

\section{B. The economic emission of hybrid system}

The inputs to the system are hourly load demand, hourly wind speed, cut-in, cut-out, rated speed of wind farm, rated power of wind farm, maximum and minimum pond level, maximum power that can be used in an hour by the unit for pumping or generating, pumping and generating efficiencies, cost and emission coefficients, maximum and minimum limits of 
Table 1. Unimodal benchmark functions

\begin{tabular}{|c|c|c|c|}
\hline Function & Dim & Range & $\mathrm{f}_{\min }$ \\
\hline $\mathrm{f}_{1}(\mathrm{x})=\sum_{\mathrm{i}=1}^{\mathrm{n}} \mathrm{x}_{\mathrm{i}}^{2}$ & 30 & {$[-100,100]$} & 0 \\
\hline $\mathrm{f}_{2}(\mathrm{x})=\sum_{\mathrm{i}=1}^{\mathrm{n}}\left|\mathrm{x}_{\mathrm{i}}\right|+\prod_{\mathrm{i}=1}^{\mathrm{n}}\left|\mathrm{x}_{\mathrm{i}}\right|$ & 30 & {$[-10,10]$} & 0 \\
\hline $\mathrm{f}_{3}(\mathrm{x})=\sum_{\mathrm{i}=1}^{\mathrm{n}}\left(\sum_{\mathrm{i}=1}^{\mathrm{i}} \mathrm{x}_{\mathrm{j}}\right)^{2}$ & 30 & {$[-100,100]$} & 0 \\
\hline $\mathrm{f}_{4}(\mathrm{x})=\max _{\mathrm{i}}\left\{\left|\mathrm{x}_{\mathrm{i}}\right|, 1 \leq \mathrm{i} \leq \mathrm{n}\right\}$ & 30 & {$[-100,100]$} & 0 \\
\hline $\mathrm{f}_{5}(\mathrm{x})=\sum_{\mathrm{i}=1}^{\mathrm{n}-1}\left[100\left(\mathrm{x}_{\mathrm{i}+1}-\mathrm{x}_{\mathrm{i}}^{2}\right)^{2}+\left(\mathrm{x}_{\mathrm{i}}-1\right)^{2}\right]$ & 30 & {$[-30,30]$} & 0 \\
\hline $\mathrm{f}_{6}(\mathrm{x})=\sum_{\mathrm{i}=1}^{\mathrm{n}}\left(\left[\mathrm{x}_{\mathrm{i}}+0.5\right]\right)^{2}$ & 30 & {$[-100,100]$} & 0 \\
\hline $\mathrm{f}_{7}(\mathrm{x})=\sum_{\mathrm{i}=1}^{\mathrm{n}} \mathrm{x}_{\mathrm{i}}^{4}+\operatorname{rand}(0.1)$ & 30 & {$[-1.28,1.28]$} & 0 \\
\hline
\end{tabular}

Table 2 Multimodal benchmark functions

\begin{tabular}{|c|c|c|c|}
\hline Function & Dim & Range & $f_{\min }$ \\
\hline $\mathrm{f}_{8}(\mathrm{x})=\sum_{\mathrm{i}=1}^{\mathrm{n}}-\mathrm{x}_{\mathrm{i}} \sin \left(\sqrt{\left|\mathrm{x}_{\mathrm{i}}\right|}\right)$ & 30 & {$[-500,500]$} & $-418.983 \times 10^{-5}$ \\
\hline$f_{9}(x)=\sum_{i=1}^{n}\left[x_{i}^{2}-10 \cos \left(2 \pi x_{i}\right)+10\right]$ & 30 & {$[-5.12,5.12]$} & 0 \\
\hline $\mathrm{f}_{10}(\mathrm{x})=-20 \exp \left(-0.2 \sqrt{\frac{1}{\mathrm{n}} \sum_{\mathrm{i}=1}^{\mathrm{n}} \mathrm{x}_{\mathrm{i}}^{2}}\right)-\exp \left(\frac{1}{\mathrm{n}} \sum_{\mathrm{i}=1}^{\mathrm{n}} \cos \left(2 \pi \mathrm{x}_{\mathrm{i}}\right)\right)+20+\mathrm{e}$ & 30 & {$[-32,32]$} & 0 \\
\hline $\mathrm{f}_{11}(\mathrm{x})=\frac{1}{4000} \sum_{\mathrm{i}=1}^{\mathrm{n}} \mathrm{x}_{\mathrm{i}}^{2}-\prod_{\mathrm{i}=1}^{\mathrm{n}} \cos \left(\frac{\mathrm{x}}{\sqrt{\mathrm{i}}}\right)+1$ & 30 & {$[-600,600]$} & 0 \\
\hline $\begin{array}{l}\mathrm{f}_{12}(\mathrm{x})=\frac{\pi}{\mathrm{n}}\left\{10 \sin \left(\pi_{\mathrm{y} 1}\right)+\sum_{\mathrm{i}=1}^{\mathrm{n}-1}\left(\mathrm{y}_{\mathrm{i}}-1\right)^{2}\left[1+10 \sin ^{2}\left(\pi \mathrm{y}_{\mathrm{i}+1}\right)\right]+(\right. \\
\quad+\sum_{\mathrm{i}=1}^{\mathrm{n}} \mathrm{u}\left(\mathrm{x}_{\mathrm{i}}, 10,100,4\right) \\
\mathrm{y}_{\mathrm{i}}=1+\frac{\mathrm{x}_{\mathrm{i}}+1}{4} \\
\mathrm{U}\left(\mathrm{x}_{\mathrm{i}}, \mathrm{a}, \mathrm{k}, \mathrm{m}\right)=\left\{\begin{array}{l}\mathrm{k}\left(\mathrm{x}_{\mathrm{i}}-\mathrm{a}\right)^{\mathrm{m}} \quad \mathrm{x}_{\mathrm{i}}>\mathrm{a} \\
\mathrm{k}\left(-\mathrm{a}<\mathrm{x}_{\mathrm{i}}<\mathrm{a}\right)^{\mathrm{m}} \mathrm{x}_{\mathrm{i}}<-\mathrm{a}\end{array}\right.\end{array}$ & 30 & {$[-50,50]$} & 0 \\
\hline $\begin{array}{l}\mathrm{f}_{13}(\mathrm{x})=0.1\left\{\sin ^{2}\left(3 \pi \mathrm{x}_{1}\right)+\sum_{\mathrm{i}=1}^{\mathrm{n}}\left(\mathrm{x}_{\mathrm{i}}-1\right)^{2}\left[1+\sin ^{2}\left(3 \pi \mathrm{x}_{\mathrm{i}}+1\right)\right]+\right. \\
\left.\left(\mathrm{x}_{\mathrm{n}}-1\right)^{2}\left[1+\sin ^{2}\left(2 \pi \mathrm{x}_{\mathrm{n}}\right)\right]\right\}+\sum_{\mathrm{i}=1}^{\mathrm{n}} \mathrm{u}\left(\mathrm{x}_{\mathrm{i}}, 5,100,4\right)\end{array}$ & 30 & {$[-50,50]$} & 0 \\
\hline
\end{tabular}


thermal generation. The input data are provided in Table 7. The outputs obtained are the hourly wind power, hourly pumped storage power, and the hourly load dispatch schedule, generation cost \& emission levels for one day for the three thermal units in three different objectives viz. most economical schedule, minimum emission schedule and best compromise EELD schedule.

The following two different cases have been considered.

- Case-1: A thermal power system with three conventional generators.

- Case-2: For the purpose of comparison, the hybrid system is considered with three conventional thermal generators, a wind generator and also a pumped storage plant.

B.1 Case 1: When only three thermal units used

- Economic dispatch(when $J_{1}$ is optimized)

Table 3. Fixed dimension multimodal benchmark functions

\begin{tabular}{|l|c|c|c|}
\hline \multicolumn{1}{|c|}{ Function } & Dim & Range & $\mathrm{f}_{\text {min }}$ \\
\hline $\mathrm{f}_{14}(\mathrm{x})=\left(\frac{1}{500}+\sum_{\mathrm{j}=1}^{25} \frac{1}{\mathrm{j}-\sum_{\mathrm{i}=1}^{2}\left(\mathrm{x}_{\mathrm{i}}-\mathrm{a}_{\mathrm{i}}\right)^{6}}\right)^{-1}$ & 2 & {$[-65,65]$} & 1 \\
\hline $\mathrm{f}_{15}(\mathrm{x})=\sum_{\mathrm{i}=1}^{11}\left[\mathrm{a}_{\mathrm{i}}-\frac{\mathrm{x}_{1}\left(\mathrm{~b}_{\mathrm{i}}^{2}+\mathrm{b}_{\mathrm{i}} \mathrm{x}_{2}\right)}{\mathrm{b}_{\mathrm{i}}^{2}+\mathrm{b}_{\mathrm{i}} \mathrm{x}_{3}+\mathrm{x}_{4}}\right]^{2}$ & 4 & {$[-5,5]$} & 0.00030 \\
\hline$f_{16}(x)=4 x_{1}^{2}-2.1 x_{1}^{4}+\frac{1}{3} x_{1}^{6}+x_{1} x_{2}-4 x_{2}^{2}+4 x_{2}^{4}$ & 2 & {$[-5,5]$} & -1.0316 \\
\hline$f_{17}(x)=\left(x_{2}-\frac{5.1}{4 \pi^{2}} x_{1}^{2}+\frac{5}{\pi} x_{1}-6\right)^{2}+10\left(1-\frac{1}{8 \mu}\right) \cos x_{1}+10$ & 2 & {$[-5,5]$} & 0.398 \\
\hline$f_{18}(x)=\left[1+\left(x_{1}+x_{2}+1\right)^{2}\left(19-14 x_{1}+3 x_{1}^{2}-14 x_{2}+6 x_{1} x_{2}+\right.\right.$ & 2 & {$[-2,2]$} & 3 \\
\hline $\left.\left.3 x_{2}^{2}\right)\right] \times\left[30+\left(2 x_{1}-3 x_{2}\right)^{2} \times\left(18-32 x_{1}+12 x_{1}^{2}+48 x_{2} * 36 x_{1} x_{2}+\right.\right.$ & 3 & {$[1,3]$} & -3.86 \\
\hline$f_{19}(x)=-\sum_{i=1}^{4} c_{i} \exp \left(-\sum_{j=1}^{3} a_{i j}\left(x_{j}-p_{i j}\right)^{2}\right)$ & 6 & {$[0,1]$} & -3.32 \\
\hline$f_{20}(x)=-\sum_{i=1}^{4} c_{i} \exp \left(-\sum_{j=1}^{6} a_{i j}\left(x_{j}-p_{i j}\right)^{2}\right)$ & 4 & {$[0,10]$} & -10.1532 \\
\hline$f_{21}(x)=-\sum_{i=1}^{5}\left[\left(X-a_{i}\right)\left(X-a_{i}\right)^{T}+c_{i}\right]^{-1}$ & 4 & {$[0,10]$} & -10.4028 \\
\hline$f_{22}(\mathrm{x})=-\sum_{\mathrm{i}=1}^{7}\left[\left(\mathrm{X}-\mathrm{a}_{\mathrm{i}}\right)\left(\mathrm{X}-\mathrm{a}_{\mathrm{i}}\right)^{\mathrm{T}}+\mathrm{c}_{\mathrm{i}}\right]^{-1}$ & {$[0,10]$} & -10.5363 \\
\hline $\mathrm{f}_{23}(\mathrm{x})=-\sum_{\mathrm{i}=1}^{10}\left[\left(\mathrm{X}-\mathrm{a}_{\mathrm{i}}\right)\left(\mathrm{X}-\mathrm{a}_{\mathrm{i}}\right)^{\mathrm{T}}+\mathrm{c}_{\mathrm{i}}\right]^{-1}$ & & & \\
\hline
\end{tabular}


Table 4. Results of unimodal benchmark functions

\begin{tabular}{|c|c|c|c|c|c|c|c|c|c|c|}
\hline \multirow{2}{*}{$F$} & \multicolumn{2}{|c|}{ SSA } & \multicolumn{2}{c|}{ GWO [22] } & \multicolumn{2}{c|}{ GSA [22] } & \multicolumn{2}{c|}{ DE [22] } & \multicolumn{2}{c|}{ PSO [22] } \\
\cline { 2 - 12 } & Ave & Std & Ave & Std & Ave & Std & Ave & Std & Ave & Std \\
\hline $\mathrm{F}_{1}$ & $2.618 \mathrm{E}-28$ & $9.86 \mathrm{E}-06$ & $6.59 \mathrm{E}-28$ & $6.34 \mathrm{E}-05$ & $2.53-\mathrm{E} 16$ & $9.67 \mathrm{E}-17$ & $8.2 \mathrm{E}-14$ & $8.2 \mathrm{E}-14$ & 0.000136 & 0.000202 \\
\hline $\mathrm{F}_{2}$ & $2.743 \mathrm{E}-17$ & 0.01952 & $7.18 \mathrm{E}-17$ & 0.029014 & 0.055655 & 0.194074 & $1.5 \mathrm{E}-09$ & $9.9 \mathrm{E}-10$ & 0.042144 & 0.045421 \\
\hline $\mathrm{F}_{3}$ & $4.98 \mathrm{E}-07$ & 24.5318 & $3.29 \mathrm{E}-06$ & 79.14958 & 896.5347 & 318.9559 & $6.8 \mathrm{E}-11$ & $7.4 \mathrm{E}-11$ & 70.12562 & 22.11924 \\
\hline $\mathrm{F}_{4}$ & $1.922 \mathrm{E}-07$ & 1.21261 & $5.61 \mathrm{E}-07$ & 1.315088 & 7.35487 & 1.741452 & 0 & 0 & 1.086481 & 0.317039 \\
\hline $\mathrm{F}_{5}$ & 26.1695 & 58.7627 & 26.81258 & 69.90499 & 67.54309 & 62.22534 & 0 & 0 & 96.71832 & 60.11559 \\
\hline $\mathrm{F}_{6}$ & 0.5009 & 0.00112 & 0.816579 & 0.012600 & $2.5 \mathrm{E}-16$ & $1.7 \mathrm{E}-16$ & 0 & 0 & 0.000102 & $8.28 \mathrm{E}-05$ \\
\hline $\mathrm{F}_{7}$ & 0.0019 & 0.1139 & 0.002213 & 0.100286 & 0.083411 & 0.04339 & 0.00463 & 0.00120 & 0.122854 & 0.044957 \\
\hline
\end{tabular}

In this case, the value of conversion factor $(C F)=\mathrm{x}=0.3632 \mathrm{lb} / \$$ is used in equation (13) to get the total cost of economic emission solution. One can find the cost of operation, emission and combined cost \& emission for the day were $36.74 \mathrm{k}$ \$/Day, $27.48 \mathrm{k}$ lb/Day and 54.9654 k \$/Day, respectively in Table 8.

Table 5 Results of multimodal benchmark functions

\begin{tabular}{|c|c|c|c|c|c|c|c|c|c|c|}
\hline \multirow{2}{*}{$F$} & \multicolumn{2}{|c|}{ SSA } & \multicolumn{2}{c|}{ GWO [22] } & \multicolumn{2}{c|}{ GSA [22] } & \multicolumn{2}{c|}{ DE [22] } & \multicolumn{2}{c|}{ PSO [22] } \\
\cline { 2 - 11 } & Ave & Std & Ave & Std & Ave & Std & Ave & Std & Ave & Std \\
\hline$F_{8}$ & -6350.1 & -3876.68 & -6123.1 & -4087.44 & -2821.07 & 493.0375 & -11080.1 & 574.7 & -4841.29 & 1152.814 \\
\hline$F_{9}$ & 6.2416 & 28.0176 & 0.310521 & 47.35612 & 25.96841 & 7.470068 & 69.2 & 38.8 & 46.70423 & 11.62938 \\
\hline$F_{10}$ & $1.18 \mathrm{E}-13$ & 0.08025 & $1.06 \mathrm{E}-13$ & 0.077835 & 0.062087 & 0.23628 & $9.7 \mathrm{E}-08$ & $4.2 \mathrm{E}-08$ & 0.276015 & 0.50901 \\
\hline $\mathrm{F}_{11}$ & 0.0122 & 0.01381 & 0.004485 & 0.006659 & 27.70154 & 5.040343 & 0 & 0 & 0.009215 & 0.007724 \\
\hline $\mathrm{F}_{12}$ & 0.0346 & 0.01269 & 0.053438 & 0.020734 & 1.799617 & 0.95114 & $7.9 \mathrm{E}-15$ & $8 \mathrm{E}-15$ & 0.006917 & 0.026301 \\
\hline $\mathrm{F}_{13}$ & 1.1886 & 1.0122 & 0.654464 & 0.004474 & 8.899084 & 7.126241 & $5.1 \mathrm{E}-14$ & $4.8 \mathrm{E}-14$ & 0.006675 & 0.008907 \\
\hline
\end{tabular}


Table 6. Results of fixed dimension multimodal benchmark functions

\begin{tabular}{|c|c|c|c|c|c|c|c|c|c|c|}
\hline \multirow{2}{*}{$F$} & \multicolumn{2}{|c|}{ SSA } & \multicolumn{2}{c|}{ GWO [22] } & \multicolumn{2}{c|}{ GSA [22] } & \multicolumn{2}{c|}{ DE [22] } & \multicolumn{2}{c|}{ PSO [22] } \\
\cline { 2 - 11 } & Ave & Std & Ave & Std & Ave & Std & Ave & Std & Ave & Std \\
\hline $\mathrm{F}_{14}$ & 2.9821 & 3.0143 & 4.042493 & 4.252799 & 5.859838 & 3.831299 & 0.998004 & $3.3 \mathrm{E}-16$ & 3.627168 & 2.560828 \\
\hline $\mathrm{F}_{15}$ & 0.000311 & 0.000617 & 0.000337 & 0.000625 & 0.003673 & 0.001647 & $4.5 \mathrm{E}-14$ & 0.00033 & 0.000577 & 0.000222 \\
\hline $\mathrm{F}_{16}$ & -1.0316 & -1.0316 & -1.03163 & -1.03163 & -1.03163 & $4.88 \mathrm{E}-16$ & -1.03163 & $3.1 \mathrm{E}-13$ & -1.03163 & $6.25 \mathrm{E}-16$ \\
\hline $\mathrm{F}_{17}$ & 0.3979 & 0.3979 & 0.397889 & 0.397887 & 0.397887 & 0 & 0.397887 & $9.9 \mathrm{E}-09$ & 0.397887 & 0 \\
\hline $\mathrm{F}_{18}$ & 3 & 3 & 3.000028 & 3 & 3 & $4.17 \mathrm{E}-15$ & 3 & $2 \mathrm{E}-15$ & 3 & $1.33 \mathrm{E}-15$ \\
\hline $\mathrm{F}_{19}$ & -3.8622 & -3.8624 & -3.86263 & -3.86278 & -3.86278 & $2.29 \mathrm{E}-15$ & NA & NA & -3.86278 & $2.58 \mathrm{E}-15$ \\
\hline $\mathrm{F}_{20}$ & -3.1973 & -3.1429 & -3.28654 & -3.25056 & -3.31778 & 0.023081 & NA & NA & -3.26634 & 0.060516 \\
\hline $\mathrm{F}_{21}$ & -10.153 & -9.6213 & -10.1514 & -9.14015 & -5.95512 & 3.737079 & -10.1532 & 0.0000025 & -6.8651 & 3.019644 \\
\hline $\mathrm{F}_{22}$ & -10.4022 & -9.2147 & -10.4015 & -8.58441 & -9.68447 & 2.014088 & -10.4029 & $3.9 \mathrm{E}-07$ & -8.45653 & 3.087094 \\
\hline $\mathrm{F}_{23}$ & -10.5354 & -9.2436 & -10.5343 & -8.55899 & -10.5364 & $2.6 \mathrm{E}-15$ & -10.5364 & $1.9 \mathrm{E}-07$ & -9.95291 & 1.782786 \\
\hline
\end{tabular}

- Emission dispatch(when $J_{2}$ is optimized)

It can also be found that the cost of operation, emission and combined cost \& emission for the day were 45.0163 k \$/Day, 26.51 k lb/Day and 55.5066 $\mathrm{k}$ \$/Day, respectively in Table 9.

- Economic emission dispatch(when $J_{3}$ is optimized)

Further it can be seen that the cost of operation, emission and combined cost \& emission for the day were $42.96 \mathrm{k} \$ / \mathrm{Day}, 26.87 \mathrm{k} \mathrm{lb} / \mathrm{Day}$ and 53.5909 k \$/Day, respectively from Table 10 . 
Table 7. Data of the three conventional thermal units

\begin{tabular}{|c|c|c|c|c|}
\hline \multicolumn{2}{|c|}{ Details } & GEN 1 & GEN 2 & GEN 3 \\
\hline \multirow{3}{*}{ Limits } & Max Limit & 200 & 150 & 125 \\
\cline { 2 - 5 } & Min Limit & 50 & 40 & 30 \\
\hline \multirow{3}{*}{$\begin{array}{c}\text { Cost } \\
\text { Coefficients }\end{array}$} & $a$ & 105 & 44.1 & 40.6 \\
\cline { 2 - 5 } & $b$ & 2.45 & 3.51 & 3.89 \\
\cline { 2 - 5 } & $c$ & 0.01 & 0.01 & 0.01 \\
\cline { 2 - 5 } & $d$ & 200 & 160 & 140 \\
\cline { 2 - 5 } & $\gamma$ & 0.035 & 0.038 & 0.04 \\
\hline \multirow{3}{*}{$\begin{array}{c}\text { Emission } \\
\text { Coefficients }\end{array}$} & $\beta$ & 0.0252 & 0.0275 & 0.0153 \\
\cline { 2 - 5 } & $\alpha$ & -1.355 & -1.249 & 0.8051 \\
\cline { 2 - 5 } & $\eta$ & 22.983 & 137.37 & 368.704 \\
\cline { 2 - 5 } & $k$ & 0.5035 & 0.5773 & 0.4966 \\
\hline
\end{tabular}

Table 8 Best cost schedule using only thermal units

\begin{tabular}{|c|c|c|c|c|c|c|c|}
\hline $\begin{array}{c}\text { Time } \\
\text { Hrs }\end{array}$ & $\begin{array}{c}\text { Demand } \\
(\mathrm{MW})\end{array}$ & $P G_{1}$ & $P G_{2}$ & $P G_{3}$ & $\begin{array}{c}\text { Cost } \\
(\mathrm{C})\end{array}$ & $\begin{array}{c}\text { Emission } \\
(\mathrm{E})\end{array}$ & $\mathrm{C}+\mathrm{x}{ }^{*} \mathrm{E}$ \\
\hline 1 & 299 & 132.8238 & 103.4645 & 62.7116 & 1.4453 & 1.0867 & 2.1734 \\
\hline 2 & 291 & 126.121 & 106.3652 & 58.5138 & 1.4063 & 1.0533 & 2.1067 \\
\hline 3 & 305 & 136.5237 & 103.2125 & 65.2638 & 1.4759 & 1.1135 & 2.2269 \\
\hline 4 & 301 & 134.3919 & 79.7266 & 86.8815 & 1.4567 & 1.0786 & 2.1571 \\
\hline 5 & 306 & 131.8608 & 109.2735 & 64.8657 & 1.484 & 1.1153 & 2.2306 \\
\hline 6 & 309 & 136.3588 & 71.661 & 100.9802 & 1.5074 & 1.1187 & 2.2373 \\
\hline 7 & 311 & 140.5608 & 87.8824 & 82.5569 & 1.5067 & 1.1273 & 2.2547 \\
\hline 8 & 317 & 140.4618 & 82.8537 & 93.6845 & 1.5431 & 1.1488 & 2.2975 \\
\hline 9 & 320 & 139.5178 & 102.7846 & 77.6976 & 1.5553 & 1.1667 & 2.3335 \\
\hline 10 & 321 & 138.5559 & 94.1166 & 88.3275 & 1.5618 & 1.16 & 2.32 \\
\hline 11 & 329 & 139.4003 & 93.4097 & 96.1899 & 1.6074 & 1.1913 & 2.3826 \\
\hline 12 & 322 & 140.6205 & 86.8256 & 94.5539 & 1.5693 & 1.167 & 2.334 \\
\hline 13 & 317 & 141.2963 & 82.9576 & 92.7461 & 1.5423 & 1.1505 & 2.3011 \\
\hline 14 & 314 & 139.0702 & 77.9754 & 96.9543 & 1.5295 & 1.1371 & 2.2742 \\
\hline 15 & 313 & 141.5164 & 75.708 & 95.7756 & 1.5242 & 1.14 & 2.2801 \\
\hline 16 & 322 & 143.543 & 104.9372 & 73.5198 & 1.5659 & 1.1875 & 2.375 \\
\hline 17 & 319 & 137.8935 & 90.024 & 91.0825 & 1.552 & 1.15 & 2.3 \\
\hline
\end{tabular}


Prakash Kumar Hota, et al.

\begin{tabular}{|c|c|c|c|c|c|c|c|}
\hline 18 & 320 & 134.9822 & 107.3069 & 77.7109 & 1.5571 & 1.162 & 2.3241 \\
\hline 19 & 327 & 138.5356 & 100.7587 & 87.7057 & 1.5944 & 1.186 & 2.3719 \\
\hline 20 & 333 & 142.0731 & 115.1726 & 75.7543 & 1.6288 & 1.237 & 2.4739 \\
\hline 21 & 331 & 139.5265 & 96.8211 & 94.6524 & 1.6176 & 1.2003 & 2.4005 \\
\hline 22 & 316 & 142.867 & 78.3925 & 94.7404 & 1.5387 & 1.1525 & 2.3049 \\
\hline 23 & 309 & 139.7132 & 80.4852 & 88.8017 & 1.4988 & 1.1184 & 2.2368 \\
\hline 24 & 303 & 138.265 & 112.4934 & 52.2416 & 1.4716 & 1.1343 & 2.2686 \\
\hline & \multicolumn{4}{|c|}{ Total } & 36.74 & 27.48 & 54.9654 \\
\hline
\end{tabular}

Table 9 Least emission schedule using only thermal units

\begin{tabular}{|c|c|c|c|c|c|c|c|}
\hline $\begin{array}{c}\text { Time in } \\
\text { Hrs }\end{array}$ & $\begin{array}{l}\text { Demand } \\
\text { (MW) }\end{array}$ & $P G_{1}$ & $P G_{2}$ & $P G_{3}$ & Cost & Emission & $\mathrm{C}+\mathrm{x} * \mathrm{E}$ \\
\hline 1 & 299 & 104.425 & 92.248 & 102.327 & 1.8361 & 1.0387 & 2.2705 \\
\hline 2 & 291 & 103.121 & 90.6404 & 97.2385 & 1.8248 & 1.0071 & 2.1362 \\
\hline 3 & 305 & 105.746 & 94.8242 & 104.43 & 1.8467 & 1.063 & 2.2911 \\
\hline 4 & 301 & 104.975 & 94.0181 & 102.007 & 1.8419 & 1.0467 & 2.1886 \\
\hline 5 & 306 & 106.69 & 95.264 & 104.047 & 1.821 & 1.0671 & 2.2207 \\
\hline 6 & 309 & 107.18 & 95.3651 & 106.455 & 1.8515 & 1.0796 & 2.3117 \\
\hline 7 & 311 & 109.877 & 95.5743 & 105.549 & 1.8554 & 1.088 & 2.2309 \\
\hline 8 & 317 & 109.139 & 98.2666 & 109.594 & 1.8736 & 1.1134 & 2.3157 \\
\hline 9 & 320 & 111.271 & 98.6351 & 110.094 & 1.8824 & 1.1263 & 2.3475 \\
\hline 10 & 321 & 111.779 & 99.97 & 109.252 & 1.8073 & 1.1307 & 2.265 \\
\hline 11 & 329 & 113.585 & 99.5795 & 115.835 & 1.9525 & 1.1659 & 2.4605 \\
\hline 12 & 322 & 111.345 & 99.2279 & 111.427 & 1.8991 & 1.135 & 2.3522 \\
\hline 13 & 317 & 109.768 & 97.6021 & 109.63 & 1.8736 & 1.1133 & 2.3361 \\
\hline 14 & 314 & 109.958 & 95.8984 & 108.144 & 1.8573 & 1.1006 & 2.2803 \\
\hline 15 & 313 & 109.497 & 95.7628 & 107.74 & 1.8563 & 1.0964 & 2.3204 \\
\hline 16 & 322 & 110.834 & 98.8689 & 112.297 & 1.9082 & 1.135 & 2.3796 \\
\hline 17 & 319 & 109.635 & 98.4658 & 110.9 & 1.8899 & 1.122 & 2.3613 \\
\hline 18 & 320 & 110.839 & 99.1801 & 109.981 & 1.8817 & 1.1263 & 2.324 \\
\hline
\end{tabular}




\begin{tabular}{|c|c|c|c|c|c|c|c|}
\hline 19 & 327 & 111.495 & 99.5896 & 115.915 & 1.952 & 1.1571 & 2.3911 \\
\hline 20 & 333 & 113.874 & 101.981 & 117.145 & 1.9711 & 1.1839 & 2.4472 \\
\hline 21 & 331 & 114.447 & 101.41 & 115.144 & 1.9475 & 1.1748 & 2.4234 \\
\hline 22 & 316 & 108.511 & 98.0627 & 109.426 & 1.8705 & 1.1091 & 2.3399 \\
\hline 23 & 309 & 105.84 & 96.2721 & 106.888 & 1.8513 & 1.0797 & 2.3057 \\
\hline 24 & 303 & 105.286 & 94.6225 & 103.091 & 1.8646 & 1.0549 & 2.207 \\
\hline Total & & & & & 45.0163 & 26.51 & 55.5066 \\
\hline
\end{tabular}

\section{B.2 Case 2: The hybrid system}

The input data of the wind generator and the pumped storage plant are provided in Table 11. It is considered that negative pumped storage power indicates the unit is operating in pumping mode thus it is consuming power from the system and positive pumped storage power indicates the unit is operating in generating mode thus it is delivering power to the system. A tabular analysis of power output from wind and pumped storage plant is provided in Table 12 . After getting almost constant output from the component 1 and 2, which is the wind and the pumped storage units, the rest part of the load demand is to be scheduled and met by the three conventional thermal units. The power output of pump storage plant, wind generator and the hybrid system are depicted in Figure. 4. The reduced load demands is shared between the three thermal units and are again scheduled in three different sub cases as given below.

Table 10 Best compromised solution using only thermal units

\begin{tabular}{|c|c|c|c|c|c|c|c|}
\hline $\begin{array}{c}\text { Time in } \\
\text { Hrs }\end{array}$ & $\begin{array}{c}\text { Demand } \\
(\mathrm{MW})\end{array}$ & $P G_{1}$ & $P G_{2}$ & $P G_{3}$ & Cost & Emission & $\mathrm{C}+\mathrm{x} * \mathrm{E}$ \\
\hline 1 & 299 & 97.7279 & 101.9528 & 99.3193 & 1.7034 & 1.0423 & 2.0865 \\
\hline 2 & 291 & 121.1898 & 71.0874 & 98.7228 & 1.5815 & 1.0279 & 2.0477 \\
\hline 3 & 305 & 121.9987 & 76.63 & 106.3713 & 1.7781 & 1.079 & 2.1655 \\
\hline 4 & 301 & 121.697 & 76.4206 & 102.8824 & 1.8251 & 1.0625 & 2.1254 \\
\hline 5 & 306 & 125.6817 & 79.0225 & 101.2958 & 1.7409 & 1.0842 & 2.1527 \\
\hline 6 & 309 & 127.2174 & 71.7301 & 110.0525 & 1.7586 & 1.1068 & 2.1934 \\
\hline 7 & 311 & 123.5207 & 80.288 & 107.1913 & 1.7981 & 1.1016 & 2.2005 \\
\hline 8 & 317 & 128.1366 & 80.6323 & 108.2311 & 1.7948 & 1.1308 & 2.255 \\
\hline 9 & 320 & 124.9872 & 92.4125 & 102.6004 & 1.8441 & 1.1338 & 2.2721 \\
\hline 10 & 321 & 113.1755 & 96.8993 & 110.9252 & 1.8015 & 1.1308 & 2.2616 \\
\hline 11 & 329 & 128.0132 & 96.4045 & 104.5824 & 1.855 & 1.1739 & 2.3478 \\
\hline 12 & 322 & 129.3874 & 84.0569 & 108.5557 & 1.8102 & 1.1504 & 2.2933 \\
\hline
\end{tabular}




\begin{tabular}{|c|c|c|c|c|c|c|c|}
\hline 13 & 317 & 134.3674 & 78.07 & 104.5626 & 1.769 & 1.1409 & 2.2562 \\
\hline 14 & 314 & 123.0089 & 89.1815 & 101.8096 & 1.8355 & 1.1082 & 2.2283 \\
\hline 15 & 313 & 102.1325 & 105.843 & 105.0246 & 1.8553 & 1.1 & 2.2255 \\
\hline 16 & 322 & 135.4707 & 90.0369 & 96.4924 & 1.8168 & 1.1566 & 2.2948 \\
\hline 17 & 319 & 135.1209 & 77.5366 & 106.3425 & 1.7653 & 1.1509 & 2.276 \\
\hline 18 & 320 & 134.6747 & 105.5439 & 79.7814 & 1.817 & 1.1587 & 2.2869 \\
\hline 19 & 327 & 125.1167 & 93.3821 & 108.5013 & 1.8494 & 1.1629 & 2.3322 \\
\hline 20 & 333 & 118.9373 & 104.6382 & 109.4246 & 1.9092 & 1.1854 & 2.3709 \\
\hline 21 & 331 & 127.7424 & 100.39 & 102.8676 & 1.858 & 1.1827 & 2.3594 \\
\hline 22 & 316 & 117.0421 & 91.7284 & 107.2294 & 1.7204 & 1.1116 & 2.2231 \\
\hline 23 & 309 & 138.0961 & 71.9083 & 98.9956 & 1.7196 & 1.1214 & 2.2033 \\
\hline 24 & 303 & 94.942 & 113.7655 & 94.2925 & 1.7568 & 1.0705 & 2.1328 \\
\hline Total & & & & & 42.96 & 26.87 & 53.5909 \\
\hline
\end{tabular}

- Economic dispatch(when $\mathrm{J}_{1}$ is optimized):

One can find the cost of operation, emission level and combined cost \& emission for the day are $32.8359 \mathrm{k} \$ /$ Day, $24.6756 \mathrm{k}$ lb/Day and $49.3515 \mathrm{k} \$$ /Day, respectively in Table 13.

Table 11. Data of the wind plant and pumped storage power plant

\begin{tabular}{|c|c|c|c|c|c|c|c|}
\hline Parameter & $V_{c i}$ & $V_{c o}$ & $V_{r}$ & $P_{r}$ & $P P_{\max }=P G_{\max }$ & $\eta_{g}$ & $\eta_{p}$ \\
\hline Value & $5 \mathrm{~m} / \mathrm{s}$ & $30 \mathrm{~m} / \mathrm{s}$ & $15 \mathrm{~m} / \mathrm{s}$ & $50 \mathrm{MW}$ & $40 \mathrm{MW}$ & 0.8447 & 0.871 \\
\hline
\end{tabular}

- Emission dispatch(when $\mathrm{J}_{2}$ is optimized)

It can also be found that the cost of operation, emission level and combined cost \& emission for the day are 43.0697 k \$/Day, $23.5423 \mathrm{k}$ lb/Day and 50.5092 k \$/Day, respectively in Table 14.

- Economic emission dispatch (when $\mathrm{J}_{3}$ is optimized)

Further, it can be seen that the cost of operation, emission level and combined cost \& emission for the day are $38.8556 \mathrm{k} \$ /$ Day, $23.8526 \mathrm{k} \mathrm{lb} /$ Day and $47.519 \mathrm{k} \$ /$ Day, respectively in Table 15. The convergence nature of the proposed algorithm is shown in Table 16. The search space is squeezed between two boundaries and converged to a single value. The curve in Figure. 5 shows the reduction of search space algorithm for all the three thermal generators. A graph is plotted between the difference of the maximum cost and minimum cost in each reduced search space in other words the convergence is shown in Figure. 6. 
Table 12 Evaluation of power output for wind farm \& pumped storage units

\begin{tabular}{|c|c|c|c|c|c|c|c|}
\hline $\begin{array}{l}\text { Time } \\
\text { in } \\
\text { hrs }\end{array}$ & $\begin{array}{l}\text { Wind } \\
\text { speed in } \\
\mathrm{m} / \mathrm{s}\end{array}$ & $\begin{array}{l}\text { Wind } \\
\text { power } \\
\text { (MW) }\end{array}$ & $\begin{array}{l}\text { Pond } \\
\text { level } \\
\text { (MW) }\end{array}$ & $\begin{array}{c}\text { Pumped } \\
\text { storage power } \\
\text { (MW) }\end{array}$ & $\begin{array}{c}\mathrm{PW}+\mathrm{PS} \\
(\mathrm{MW})\end{array}$ & $\begin{array}{l}\text { Demand } \\
\text { (MW) }\end{array}$ & $\begin{array}{c}\text { PD for } \\
\text { thermal } \\
(\mathrm{MW})\end{array}$ \\
\hline 1 & 35 & 42.8571 & 11.1986 & -11.1986 & 31.6586 & 299 & 267.3414 \\
\hline 2 & 34 & 41.4286 & 21.1529 & -9.9543 & 31.4743 & 291 & 259.5257 \\
\hline 3 & 36 & 44.2857 & 33.5957 & -12.4429 & 31.8429 & 305 & 273.1571 \\
\hline 4 & 33 & 40 & 42.3057 & -8.71 & 31.29 & 301 & 269.71 \\
\hline 5 & 26 & 30 & 42.3057 & 0 & 30 & 306 & 276 \\
\hline 6 & 36 & 44.2857 & 54.7486 & -12.4429 & 31.8429 & 309 & 277.1571 \\
\hline 7 & 36 & 44.2857 & 67.1914 & -12.4429 & 31.8429 & 311 & 279.1571 \\
\hline 8 & 36 & 44.2857 & 79.6343 & -12.4429 & 31.8429 & 317 & 285.1571 \\
\hline 9 & 35 & 42.8571 & 90.8329 & -11.1986 & 31.6586 & 320 & 288.3414 \\
\hline 10 & 36 & 44.2857 & 100 & -9.1671 & 35.1186 & 321 & 285.8814 \\
\hline 11 & 22 & 24.2857 & 93.2351 & 6.7649 & 31.0506 & 329 & 297.9494 \\
\hline 12 & 19 & 20 & 81.3966 & 11.8385 & 31.8385 & 322 & 290.1615 \\
\hline 13 & 17 & 17.1429 & 66.1756 & 15.221 & 32.3638 & 317 & 284.6362 \\
\hline 14 & 12 & 10 & 42.4986 & 23.677 & 33.677 & 314 & 280.323 \\
\hline 15 & 12 & 10 & 18.8216 & 23.677 & 33.677 & 313 & 279.323 \\
\hline 16 & 19 & 20 & 6.983 & 11.8385 & 31.8385 & 322 & 290.1615 \\
\hline 17 & 28 & 32.8571 & 9.4716 & -2.4886 & 30.3686 & 319 & 288.6314 \\
\hline 18 & 34 & 41.4286 & 19.4259 & -9.9543 & 31.4743 & 320 & 288.5257 \\
\hline 19 & 36 & 44.2857 & 31.8688 & -12.4429 & 31.8429 & 327 & 295.1571 \\
\hline 20 & 12 & 10 & 8.1917 & 23.677 & 33.677 & 333 & 299.323 \\
\hline 21 & 15 & 14.2857 & 0 & 8.1917 & 22.4774 & 331 & 308.5226 \\
\hline 22 & 19 & 20 & 0 & 0 & 20 & 316 & 296 \\
\hline 23 & 28 & 32.8571 & 2.4886 & -2.4886 & 30.3686 & 309 & 278.6314 \\
\hline 24 & 22 & 24.2857 & 0 & 2.4886 & 26.7743 & 303 & 276.2257 \\
\hline
\end{tabular}

The best cost solution, least emission solution and best compromising solution for both the systems; those are with the three conventional thermal units only and for the hybrid system are summarized in the Table 17. In hybrid system, the net saving of cost and emission level are found to be $4.1044 \mathrm{k} \$$ /Day and $3.0174 \mathrm{k} \mathrm{lb} /$ Day, respectively in comparison to power system having only thermal generators.

From Figures 4-6 and Table 17, it is very clear that space search algorithm having good convergence characteristics and yields better results in a hybrid system. 
Prakash Kumar Hota, et al.

Table 13. Best cost schedule for three thermal units in the hybrid system

\begin{tabular}{|c|c|c|c|c|c|c|c|}
\hline Time & Thermal Demand & GEN 1 & GEN 2 & GEN 3 & Cost & Emc & C+x*E \\
\hline 1 & 267.3414 & 141.0819 & 65.0119 & 61.2476 & 1.2806 & 0.9954 & 1.9909 \\
\hline 2 & 259.5257 & 124.6683 & 76.8503 & 58.0072 & 1.2387 & 0.9287 & 1.8575 \\
\hline 3 & 273.1571 & 138.5146 & 79.6883 & 54.9543 & 1.3081 & 1.0051 & 2.0102 \\
\hline 4 & 269.71 & 134.8567 & 70.8858 & 63.9674 & 1.2908 & 0.982 & 1.9641 \\
\hline 5 & 276 & 119.2089 & 97.2987 & 59.4924 & 1.3269 & 0.9806 & 1.9613 \\
\hline 6 & 277.1571 & 127.8813 & 67.1335 & 82.1423 & 1.3343 & 0.9907 & 1.9814 \\
\hline 7 & 279.1571 & 126.1643 & 74.0475 & 78.9454 & 1.3422 & 0.9898 & 1.9797 \\
\hline 8 & 285.1571 & 135.3343 & 64.893 & 84.9298 & 1.3769 & 1.0353 & 2.0706 \\
\hline 9 & 288.3414 & 139.9532 & 65.7299 & 82.6584 & 1.3922 & 1.0561 & 2.1122 \\
\hline 10 & 285.8814 & 137.169 & 87.9301 & 60.7824 & 1.3733 & 1.0412 & 2.0824 \\
\hline 11 & 297.9494 & 139.4742 & 74.1452 & 84.33 & 1.4403 & 1.0816 & 2.1631 \\
\hline 12 & 290.1615 & 134.8157 & 67.9964 & 87.3494 & 1.4027 & 1.0486 & 2.0972 \\
\hline 13 & 284.6362 & 136.2946 & 72.6609 & 75.6807 & 1.3689 & 1.0302 & 2.0604 \\
\hline 14 & 280.323 & 124.892 & 84.2865 & 71.1444 & 1.3459 & 0.9915 & 1.9829 \\
\hline 15 & 279.323 & 132.0817 & 97.8384 & 49.4029 & 1.3435 & 1.0235 & 2.047 \\
\hline 16 & 290.1615 & 130.8992 & 72.4189 & 86.8433 & 1.4016 & 1.0371 & 2.0743 \\
\hline 17 & 288.6314 & 131.153 & 105.5377 & 51.9408 & 1.3939 & 1.0593 & 2.1186 \\
\hline 18 & 288.5257 & 129.5307 & 69.8658 & 89.1293 & 1.395 & 1.031 & 2.0619 \\
\hline 19 & 295.1571 & 135.8325 & 72.9305 & 86.3941 & 1.4269 & 1.0643 & 2.1286 \\
\hline 20 & 299.323 & 129.7475 & 75.9904 & 93.585 & 1.452 & 1.066 & 2.132 \\
\hline 21 & 308.5226 & 139.5278 & 78.6823 & 90.3125 & 1.4972 & 1.117 & 2.234 \\
\hline 22 & 296 & 137.0593 & 107.9091 & 51.0315 & 1.4331 & 1.1014 & 2.2028 \\
\hline 23 & 278.6314 & 129.2533 & 71.6595 & 77.7186 & 1.339 & 0.9952 & 1.9904 \\
\hline 24 & 276.2257 & 139.59 & 57.5155 & 79.1203 & 1.3319 & 1.024 & 2.048 \\
\hline Total & & & & & 32.8359 & 24.6756 & 49.3515 \\
\hline
\end{tabular}


Table 14 Least emission schedule for three thermal units in the hybrid system

\begin{tabular}{|c|c|c|c|c|c|c|c|}
\hline Time & $\begin{array}{c}\text { Thermal } \\
\text { Demand }\end{array}$ & GEN 1 & GEN 2 & GEN 3 & Cost & Emc & C+x*E \\
\hline 1 & 267.3414 & 95.5374 & 85.0861 & 86.718 & 1.7864 & 0.9191 & 2.0347 \\
\hline 2 & 259.5257 & 91.8277 & 82.7786 & 84.9193 & 1.7569 & 0.892 & 2.0138 \\
\hline 3 & 273.1571 & 98.2335 & 86.321 & 88.6027 & 1.8057 & 0.94 & 1.9991 \\
\hline 4 & 269.71 & 96.4623 & 85.7797 & 87.4681 & 1.6297 & 0.9276 & 1.9305 \\
\hline 5 & 276 & 97.9284 & 87.4965 & 90.5751 & 1.7902 & 0.9503 & 2.0578 \\
\hline 6 & 277.1571 & 99.1554 & 87.2867 & 90.715 & 1.794 & 0.9546 & 2.085 \\
\hline 7 & 279.1571 & 98.3225 & 88.7395 & 92.0952 & 1.8182 & 0.962 & 2.0653 \\
\hline 8 & 285.1571 & 100.57 & 89.8299 & 94.7572 & 1.8435 & 0.9846 & 2.1075 \\
\hline 9 & 288.3414 & 101.9155 & 90.1432 & 96.2828 & 1.7244 & 0.9968 & 2.0636 \\
\hline 10 & 285.8814 & 100.7006 & 89.6114 & 95.5695 & 1.7282 & 0.9873 & 2.0698 \\
\hline 11 & 297.9494 & 104.4928 & 92.9644 & 100.4921 & 1.8372 & 1.0345 & 2.2416 \\
\hline 12 & 290.1615 & 102.3672 & 91.3438 & 96.4505 & 1.8409 & 1.0038 & 2.1436 \\
\hline 13 & 284.6362 & 99.9814 & 89.415 & 95.2398 & 1.81 & 0.9826 & 2.1751 \\
\hline 14 & 280.323 & 99.2783 & 88.6683 & 92.3763 & 1.8018 & 0.9663 & 2.0984 \\
\hline 15 & 279.323 & 99.074 & 87.8119 & 92.437 & 1.798 & 0.9626 & 2.0918 \\
\hline 16 & 290.1615 & 102.813 & 90.6295 & 96.719 & 1.7644 & 1.0038 & 2.1137 \\
\hline 17 & 288.6314 & 101.4196 & 90.9125 & 96.2993 & 1.8671 & 0.9979 & 2.1012 \\
\hline 18 & 288.5257 & 101.3939 & 90.7183 & 96.4135 & 1.7736 & 0.9975 & 2.0538 \\
\hline 19 & 295.1571 & 103.4257 & 92.1956 & 99.5358 & 1.832 & 1.0234 & 2.2681 \\
\hline 20 & 299.323 & 104.7031 & 93.3515 & 101.2683 & 1.7944 & 1.04 & 2.1673 \\
\hline 21 & 308.5226 & 107.493 & 95.2723 & 105.7572 & 1.8515 & 1.0776 & 2.3072 \\
\hline 22 & 296 & 104.9212 & 92.0056 & 99.0731 & 1.8345 & 1.0267 & 2.2508 \\
\hline 23 & 278.6314 & 99.039 & 87.4876 & 92.1048 & 1.7963 & 0.9601 & 2.032 \\
\hline 24 & 276.2257 & 97.5576 & 87.9627 & 90.7054 & 1.7908 & 0.9512 & 2.0375 \\
\hline & Total & & & & 43.0697 & 23.5423 & 50.5092 \\
\hline
\end{tabular}




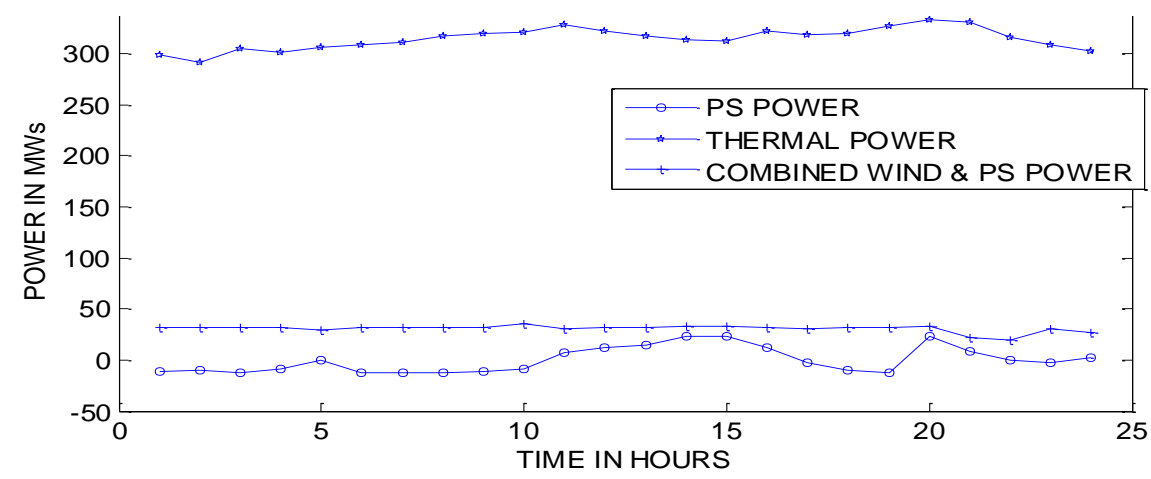

Figure.4 Load shared by each component of the hybrid system

Table 15. Best compromised solution schedule for the 3 thermal units in the hybrid system

\begin{tabular}{|c|c|c|c|c|c|c|c|}
\hline Time & $\begin{array}{c}\text { Thermal } \\
\text { Demand }\end{array}$ & GEN 1 & GEN 2 & GEN 3 & Cost & Emc & C $+\mathrm{x}^{*} \mathrm{E}$ \\
\hline 1 & 267.3414 & 73.5836 & 94.7282 & 99.0296 & 1.6208 & 0.9369 & 1.8602 \\
\hline 2 & 259.5257 & 107.801 & 62.0217 & 89.7031 & 1.3848 & 0.9106 & 1.8093 \\
\hline 3 & 273.1571 & 81.2281 & 96.2231 & 95.7059 & 1.68 & 0.95 & 1.9009 \\
\hline 4 & 269.71 & 85.8231 & 100.3053 & 83.5816 & 1.52 & 0.937 & 1.8666 \\
\hline 5 & 276 & 95.4103 & 93.6516 & 86.9382 & 1.6528 & 0.952 & 1.9106 \\
\hline 6 & 277.1571 & 116.6405 & 63.8367 & 96.6798 & 1.6835 & 0.9799 & 1.936 \\
\hline 7 & 279.1571 & 83.7703 & 107.3014 & 88.0854 & 1.5652 & 0.9791 & 1.9412 \\
\hline 8 & 285.1571 & 92.5365 & 107.8185 & 84.8021 & 1.4263 & 0.9977 & 1.9954 \\
\hline 9 & 288.3414 & 85.4751 & 110.0752 & 92.7911 & 1.6124 & 1.0151 & 2.0124 \\
\hline 10 & 285.8814 & 119.2834 & 76.7858 & 89.8123 & 1.7456 & 1.0015 & 1.9897 \\
\hline 11 & 297.9494 & 116.5825 & 77.1928 & 104.1741 & 1.5961 & 1.0457 & 2.0904 \\
\hline 12 & 290.1615 & 85.4112 & 110.0788 & 94.6714 & 1.6281 & 1.022 & 2.026 \\
\hline 13 & 284.6362 & 111.3925 & 78.6867 & 94.557 & 1.555 & 0.989 & 1.9754 \\
\hline 14 & 280.323 & 88.453 & 101.6027 & 90.2673 & 1.7369 & 0.9746 & 1.9458 \\
\hline 15 & 279.323 & 114.106 & 73.3999 & 91.8171 & 1.4974 & 0.9748 & 1.9456 \\
\hline 16 & 290.1615 & 119.4441 & 73.6663 & 97.0511 & 1.6738 & 1.0202 & 2.0248 \\
\hline 17 & 288.6314 & 102.0909 & 94.1927 & 92.3479 & 1.6004 & 0.9986 & 1.9965 \\
\hline 18 & 288.5257 & 101.0572 & 97.0948 & 90.3737 & 1.5081 & 0.9994 & 1.9987 \\
\hline 19 & 295.1571 & 110.9231 & 71.2592 & 112.9749 & 1.7287 & 1.0405 & 2.0718 \\
\hline 20 & 299.323 & 98.9213 & 104.8682 & 95.5335 & 1.6355 & 1.0454 & 2.0874 \\
\hline 21 & 308.5226 & 129.3367 & 72.4571 & 106.7287 & 1.7422 & 1.1058 & 2.1839 \\
\hline 22 & 296 & 84.6236 & 111.6186 & 99.7577 & 1.7309 & 1.0472 & 2.0791 \\
\hline 23 & 278.6314 & 110.3047 & 99.0054 & 69.3213 & 1.5983 & 0.9753 & 1.9452 \\
\hline 24 & 276.2257 & 90.0101 & 86.3412 & 99.8744 & 1.7328 & 0.9543 & 1.9261 \\
\hline Total & & & & & 38.8556 & 23.8526 & 47.519 \\
\hline
\end{tabular}




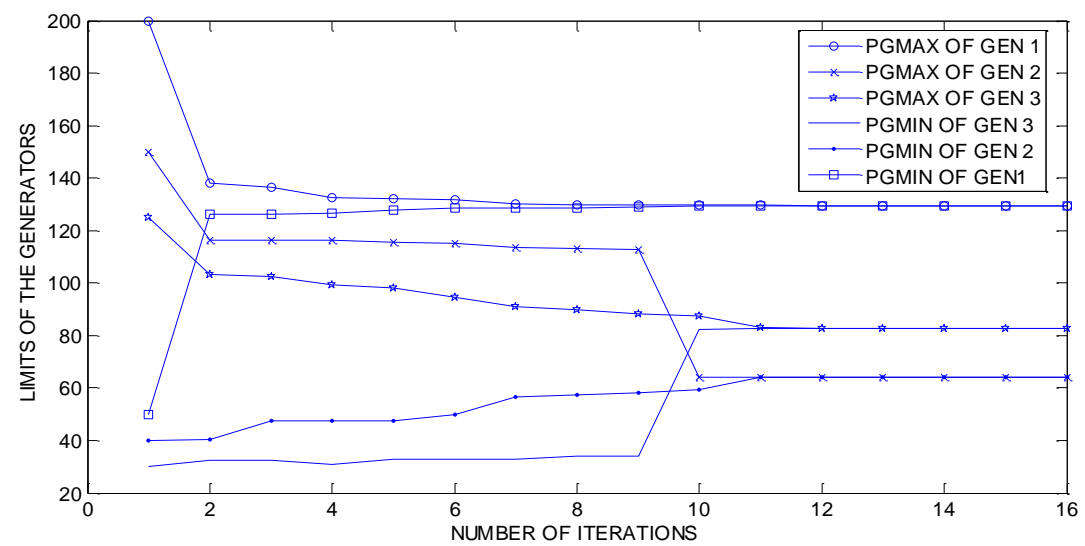

Figure 5. Reduction of space to be searched in each iteration

Table 16. Convergence of space search between two boundaries within 15 iterations for the three thermal generators

\begin{tabular}{|c|c|c|c|c|c|c|}
\hline \multicolumn{3}{|c|}{$P G_{\max }(\mathrm{MW})$} & & \multicolumn{3}{c|}{$P G_{\min }(\mathrm{MW})$} \\
\hline GEN 1 & GEN 2 & GEN 3 & DIFF & GEN 1 & GEN 2 & GEN 3 \\
\hline 200 & 150 & 125 & & 50 & 40 & 30 \\
\hline 142.4583 & 122.8714 & 109.876 & 341.5951 & 50.0612 & 40.7565 & 31.5893 \\
\hline 141.5843 & 120.3753 & 91.6122 & 337.684 & 120.8539 & 43.0293 & 30.8242 \\
\hline 135.9113 & 119.4343 & 49.4843 & 301.8613 & 121.7976 & 104.9438 & 31.0589 \\
\hline 123.0747 & 111.1722 & 48.2051 & 44.1508 & 122.4031 & 105.359 & 42.6504 \\
\hline 122.8861 & 106.7677 & 47.7999 & 12.7034 & 122.5237 & 105.5808 & 46.7493 \\
\hline 122.7713 & 106.1321 & 47.7316 & 2.8002 & 122.6162 & 105.7395 & 47.4087 \\
\hline 122.7653 & 105.9536 & 47.7101 & 1.2807 & 122.6962 & 105.7794 & 47.566 \\
\hline 122.7523 & 105.8506 & 47.6861 & 0.8241 & 122.7052 & 105.8058 & 47.656 \\
\hline 122.7332 & 105.8306 & 47.6828 & 0.3924 & 122.7123 & 105.8117 & 47.6745 \\
\hline 122.7327 & 105.8246 & 47.6823 & 0.1477 & 122.7239 & 105.8128 & 47.6772 \\
\hline 122.7326 & 105.8199 & 47.6811 & 0.102 & 122.7258 & 105.814 & 47.6791 \\
\hline 122.7302 & 105.8187 & 47.681 & 0.065 & 122.7266 & 105.815 & 47.68 \\
\hline 122.7292 & 105.8175 & 47.6808 & 0.0337 & 122.7276 & 105.8158 & 47.6805 \\
\hline 122.7289 & 105.8167 & 47.6808 & 0.0178 & 122.7283 & 105.8161 & 47.6807 \\
\hline 122.7289 & 105.8167 & 47.6808 & 0.0067 & 122.7283 & 105.8161 & 47.6807 \\
\hline
\end{tabular}




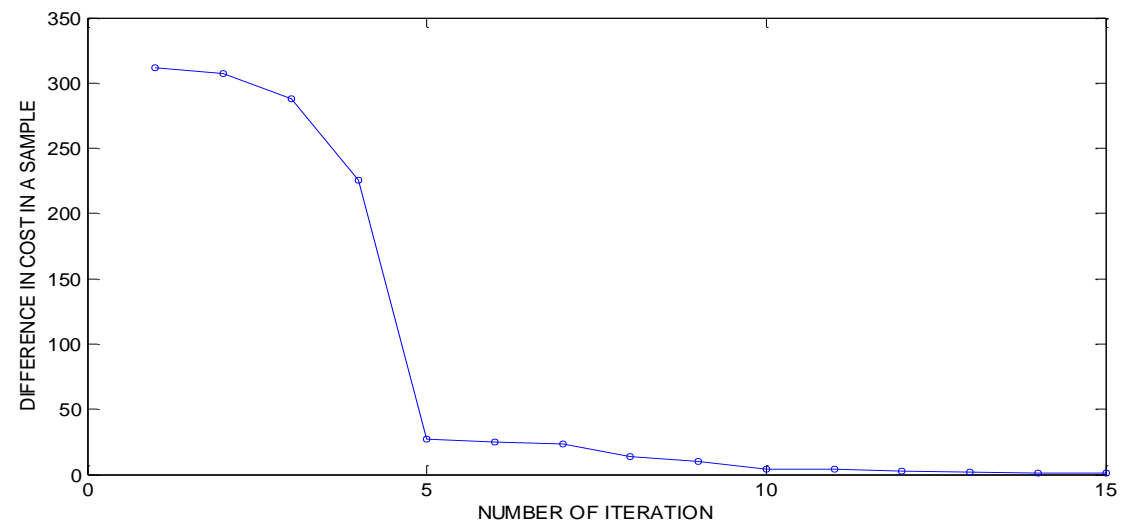

Figure 6. Convergence obtained by using the proposed algorithm

Table 17. The best cost, minimum emission level and compromised cost of operation are compared between two system

\begin{tabular}{|c|c|c|c|c|}
\hline \multicolumn{2}{|c|}{ Cases } & $\begin{array}{c}\text { Cost } \\
(\mathrm{k} \$ / \text { Day })\end{array}$ & $\begin{array}{c}\text { Emission } \\
(\mathrm{k} \text { lb/Day })\end{array}$ & $\begin{array}{c}\text { Cost+ } \\
\text { Emission } \\
(\mathrm{k} \text { \$/Day })\end{array}$ \\
\hline \multirow{4}{*}{$\begin{array}{c}\text { Thermal } \\
\text { System }\end{array}$} & best cost & 36.74 & 27.48 & 54.9654 \\
\cline { 2 - 5 } & least emission & 45.0163 & 26.51 & 55.5066 \\
\cline { 2 - 5 } & compromised & 42.96 & 26.87 & 53.5909 \\
\hline \multirow{3}{*}{$\begin{array}{c}\text { Hybrid } \\
\text { System }\end{array}$} & $\begin{array}{c}\text { minimum } \\
\text { emission }\end{array}$ & 43.0697 & 23.5423 & 50.5092 \\
\cline { 2 - 5 } & compromised & 38.8556 & 23.8526 & 47.519 \\
\hline
\end{tabular}

\section{Conclusion}

This paper described an efficient algorithm as space search algorithm based on fuzzy coordination method which has been applied to a hybrid system. Initially, twenty three test functions were employed in order to benchmark the performance of the proposed algorithm. The results confirmed that SSA was able to provide highly competitive results compared to other established heuristic methods such as DE, PSO, GSA and GWO. Moreover, the results obtained by SSA with challenging search spaces provide superior performance. The proposed method is applied to a real hybrid system comprising of pump storage plant, wind generator and thermal generators to solve EELD problem with equality and inequality constraints. The original two objectives are transformed into a single objective optimization problem by using fuzzy logic by maximizing the membership function. The optimization computation is conducted on two test power systems. The hybrid system yields better efficient economic dispatch results than the conventional power system. Security and reliability analysis along with probabilistic wind model may be adopted using the proposed algorithm. 


\section{References}

[1]. John Hetzer, David C. Yu and Kalu Bhattarai, "An economic dispatch model incorporating wind power", IEEE Transactions on Energy Conversion, Vol.23, No 2, pp. 603-611, June 2008.

[2]. Edgardo D. Castronuovo and J. A. Peças Lopes, "On the Optimization of the Daily Operation of a Wind-Hydro Power Plant", IEEE Transactions on Power Systems, Vol. 19, No. 3, pp. 1599-1606, August 2004.

[3]. J. Garcia-Gonzalez, R. Moraga, Luz Matres Santos and Alicia Matro Gonzalez, "Stochastic joint optimization of wind generation and pumped-storage units in an electricity market", IEEE Transactions on Power Systems, Vol.23, No 2, pp. 460-467, May 2008.

[4]. V.S. Pappala, I. Erlich and S.N. Singh, "Unit commitment under wind power and demand uncertainties", (C2008 IEEE.

[5]. Eleanor Denny and Mark O' Malley, "Wind generation, power system operation and emissions reduction", IEEE Transactions on Power Systems, Vol.21, No 1, pp. 341-347, February 2008.

[6]. A.T.Al-Awami, E.Sortomme and M.A.El-Sharkawi,"Optimizing economic/environmental dispatch with wind and thermal units", (C2009 IEEE.

[7]. V. Miranda and P. S. Hang, "Economic dispatch model with fuzzy wind constraints and attitudes of dispatchers", IEEE Trans. Power Syst., Vol. 20, No. 4, pp. 2143-2145, Nov. 2005.

[8]. Tzyy-Chyang Lu and Jyh-Ching Juang, "An Evolutionary space search algorithm for Global Numerical optimization", Joint 48th IEEE Conference on Decision and Control and $28^{\text {th }}$ Chinese Control Conference, Shanghai, December 16-18, 2009.

[9]. Wei Huang, Sung K-wun Oh, Zhaolu Guo, Witold Pedrycz, "A space search optimization algorithm with accelerated convergence strategies", Applied Soft Computing, Vol. 13, 2013. Pp. 4659-4675.

[10]. S. Papaefthimiou, E. Karamanou, S. Papathanassiou, "Operating Policies for WindPumped Storage Hybrid Power Stations in Island Grids", IET Renewable Power Generation, Vol. 3, No. 3, Sept. 2009, pp. 293-307.

[11]. M. Tripathy, A. K. Barisal," Bacteria Foraging Algorithm based Economic Load Dispatch with Wind Energy" IEEE conference World Congress on Nature \& Biologically Inspired Computing (NaBIC), December 2009, pp. 1327-1332.

[12]. Warsono, D. King, C. Ozveren, and D. Bradley, "Economic load dispatch optimization of renewable energy in power system using genetic algorithm," in Power Tech, 2007 IEEE Lausanne, July 2007, pp. 2174-2179.

[13]. A.D. Belgunda, J.S. Arora, "A Study of mathematical programming methods for structural optimization. Part I: Theory”, Int J Numer Meth Eng 1985; 21:1583-99.

[14]. C.A.C. Coello, E.M. Montes, "Constraint-handling in genetic algorithms through the use of dominance-based tournament selection", Adv Eng Inform 2002;16:193-203.

[15]. Q. He, L. Wang, "An effective co-evolutionary particle swarm optimization for constrained engineering design problems”, Eng Appl Artif Intell 2007; 20:89-99.

[16]. E.M. Montes, C.A.C. Coello, "An empirical study about the usefulness of evolution strategies to solve constrained optimization problems", Int J Gen Syst 2008; 37:443-73.

[17]. C.A.C. Coello, "Use of a self-adaptive penalty approach for engineering optimization problems", Comput Ind 2000; 41:113-27.

[18]. M. Mahdavi, M. Fesanghary, E. Damangir, “An improved harmony search algorithm for solving optimization problems", Appl Math Comput 2007; 188:1567-79.

[19]. F. Huang, L. Wang, Q. He, "An effective co-evolutionary differential evolution for constrained optimization”, Appl Math Comput 2007; 186: 340-56. 
[20]. X.S. Yang, "Nature-inspired metaheuristic algorithms", Luniver Press; 2011. Carlos, C. Coello, "Constraint-handling using an evolutionary multiobjective optimization technique", Civil Eng Syst 2000;17:319-46.

[21]. S. Mirjalili, S.M. Mirjalili, A. Lewis, "Grey wolf optimizer", Int J of Advances in Engineering software 2014; 69:46-61.

\section{LIST OF NOTATIONS USED}

Dim: Dimension of benchmark function

$f_{\min }=$ Optimum function value

$P_{w}(t)=$ the wind power output in MW at time $t$.

$V(t)=$ the wind speed in $\mathrm{m} / \mathrm{s}$ at time $t$.

$V_{c i}=$ the cut in speed.

$V_{c o}=$ the cut out speed.

$V_{r}=15 \mathrm{~m} / \mathrm{sec}$, is the rated wind speed.

$P_{r}=50 \mathrm{MW}$, is the rated output power of the wind farm.

$P L_{t}=$ Pond level expressed in terms of MW at time $t$.

$M=1 \mathrm{hr}$, is the time interval.

$P G_{t}=$ power generated by pumped storage unit at time $\mathrm{t}$ in MW.

$P P_{t}=$ power used for pumping by the unit at time $t$ in MW.

$P P_{\max }=P G_{\max }$, the max power that can be used for pumping or generating by the unit in an hour

$\eta_{g}=$ the generating efficiency of the pumped storage unit

$\eta_{p}=$ pumping efficiency of the pumped storage unit $J_{1}=$ objective function for least cost.

$J_{2}=$ objective function for least emission

$J_{3}=$ objective function for best compromising solution

$C F=\operatorname{Min}(E m c) / \operatorname{Min}($ Cost $)$ in a sample space, is the conversion factor

$E m c=$ operating emission that is specified by equation .

$O C=$ operating cost that is specified by equation.

$P_{i}=$ output of the $i^{\text {th }}$ generator

$n=$ the number of thermal generators 


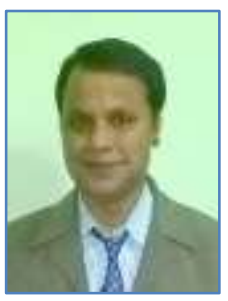

Prakash Kumar Hota was born in 1963 in India. He has graduated in Electrical and Electronics Engineering from the National Institute of Technology (NIT), Tiruchirapalli, India in 1985, received his M.Tech in Industrial Power Control \& Electric Drives in 1992 from Sambalpur University, India and Ph.D in Electrical Engineering from Jadavpur University, Kolkata, India in 1999. Currently, he is a Professor of Electrical Engineering and Dean of Centre for Distance and Continuing Education (CDCE) at Veer Surendra Sai University of Technology (VSSUT), Burla, India. His research interests include Economic Emission Load Dispatch, Hydrothermal Scheduling, Hybrid Power Generation Systems, Power Quality and Soft Computing applications to different Power System Problems in Deregulated Environment.

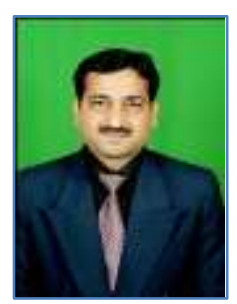

Nakul Charan Sahu was born in 1965 and received the A.M.I.E (Electrical) degree from Institution of Engineers (India) in 1988 and the M.Tech in Power System Engineering from University College of Engineering (Now, VSSUT), Burla, India in 1992 and now a sponsored Ph. D scholar at VSSUT, Burla, India. Currently, he has been with the Electrical Engineering Department, ITER, SOA University, Bhubaneswar, India, where he is an Assistant Professor. His research interests include Economic Load Dispatch, Hydrothermal Scheduling, Hybrid Generation Systems, etc.

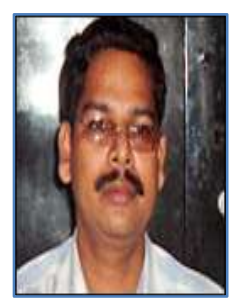

Ajit Kumar Barisal was born in 1975 and received the B.E. degree from the U.C.E, Burla (now VSSUT), Odisha,India in 1998 and the M.E.E. degree in power system from Bengal Engineering College (now IIEST), Shibpur, Howrah, in 2001 and Ph. D degree from Jadavpur University, Kolkata in 2010, all in electrical engineering. Currently, he has been with the Electrical Engineering Department, V.S.S University of Technology, Burla, Odisha, where he is an Associate Professor. His research interests include Economic Load Dispatch, Hydrothermal Scheduling, Alternative Energy Power Generation and Soft Computing Applications to different Power System Problems. 